\title{
Predictors of inadequate bowel preparation using two liters of polyethylene glycol for colonoscopy Parajuli A $\mathrm{A}^{\mathrm{iD}}$, KC N²
}

${ }^{1}$ Anuj Parajuli, Lecturer, Department of Surgery; ${ }^{2}$ Niranjan KC, MBBS Graduate, Kathmandu Medical College Teaching Hospital, Kathmandu, Nepal.

\begin{abstract}
Background: Inadequate bowel preparation can result in missed pathological lesions and cancellation of procedures thereby increasing the cost and delay in the diagnosis.

Objectives: Thes aim of the study was to identify the potential predictors of inadequate bowel preparation using 2 liters of polyethylene glycol solution.

Methodology: A prospective study was done, which included 138 consecutive patients who underwent colonoscopy over a period of 6 months. Patient's demographics, medical history, and preparation quality were collected and compared. Factors associated with inadequate bowel preparation were identified by univariate statistics and multivariate logistical regression analysis.

Results: Out of 138 colonoscopy procedure, 119 (86.2\%) preparations were adequate and 19 (13.8\%) were inadequate. The mean age of the patient was 52.62 (SD \pm 10.51 ) years. Out of which, $82(59.4 \%)$ were male and $56(40.6 \%)$ were female. In the multivariate regression analysis, constipation [adjusted OR $8.55,95 \% \mathrm{Cl} 1.79-41.67$ ] and non-compliance [adjusted OR 58.82, 95\% Cl 5.99-500] were independently associated with inadequate bowel preparation.

Conclusion: Constipation, non-compliance, overweight, neurological disorders like stroke, dementia and age $>60$ years were associated with inadequate bowel preparation. Early identification of patients with a high risk of inadequate preparation can be salvaged with change in bowel cleaning strategy.
\end{abstract}

Key words: Colonoscopy; Inadequate bowel preparation; Polyethylene glycol.

\section{INTRODUCTION}

Colonoscopy is a key investigation for screening, diagnosis and therapeutic procedure of colon and rectal disorders. It also enables procedures like biopsy and

Access this article online

Website: www.jkmc.com.np

DOI: https://doi.org/10.3126/jkmc.v9i3.36417

\section{HOW TO CITE}

Parajuli A, KC N. Predictors of inadequate bowel preparation using two liters of polyethylene glycol for colonoscopy. J Kathmandu Med Coll. 2020;9(3):144-9.

Address for correspondence

\section{Dr. Anuj Parajuli}

Department of Surgery

Kathmandu Medical College Teaching Hospital

Kathmandu, Nepal

E-mail: dranujparajuli@yahoo.com

Copyright @ 2020 Journal of Kathmandu Medical College (JKMC)

ISSN: 2019-1785 (Print), 2091-1793 (Online)

(i) (S) This work is licensed under a Creative Commons Attribution-Non Commercial 4.0 International License. treatment of polyps and superficial colorectal tumors. It is estimated that about one third of the colonoscopy procedures is performed for screening purposes'.

Adequate bowel preparation is essential for the successful completion of colonoscopy procedures. Inadequate preparation has an adverse impact on the procedure efficiency and diagnostic yield thereby decreasing the colonic adenoma detection rate and increasing the cost associated with repeated procedures and delay in diagnosis ${ }^{2}$. According to a French epidemiological survey in 1.2 million colonoscopy procedures, about $40 \%$ had procedure failure due to inadequate bowel preparation and $5 \%$ had redo colonoscopy ${ }^{3}$. It has also been reported that about $20-25 \%$ of bowel preparation are inadequate $e^{4,5}$.

An ideal bowel cleansing agent should be effective in cleaning the bowel, well-tolerated, and convenient to use, with minimal side effects. Numerous studies are comparing the superiority of different solutions available for bowel preparation in an attempt to improve the 
ways of colonic preparation, with polyethylene glycol (PEG) and Sodium Phosphate (NaP); which is the widely used formulas ${ }^{6}$. However, no one regimen is superior to others in terms of completeness. Recently, it has been mentioned that certain diseases (stroke, diabetes, dementia) ${ }^{7}$ demographic factors (age, sex, body mass index) ${ }^{8}$ and medications (calcium channel blockers, tri-cyclic antidepressant, opioids) $)^{9,10}$ are associated with incomplete preparation. Other factors include noncompliance due to discomfort in consuming the solution $^{11}$ and timing of bowel preparation ${ }^{12}$.

The aim of this study was to assess the predictive factors of inadequate bowel preparation and identify those patients who are at high risk for inadequate bowel preparation before colonoscopy procedure so that alternative preparation regimen can be planned accordingly.

\section{METHODOLOGY}

A prospective observational study was conducted from June 2019 to November 2019 at Kathmandu Medical College \& Teaching Hospital. All patients (>18years) who underwent a routine colonoscopy, irrespective of indications were eligible for the study. Colonoscopy failure was defined as incomplete colonoscopy (no cecal intubation), or complete colonoscopy but requiring a further check colonoscopy due to poor bowel preparation. All participants received verbal and written instructions (English and Nepali) that included a structured low-fiber diet on second pre procedure days and only liquids on the night before the procedure. Patients were instructed how to mix and drink the bowel preparation solution [ A sachet of PEG dissolved in $2 \mathrm{~L}$ water, two $5 \mathrm{mg}$ bisacodyl tablets at $2 \mathrm{pm}$ followed by 8 oz of PEG solution and oral rehydration solution (ORS) every 15 minutes between $5 \mathrm{pm}-8 \mathrm{pm}$ the night before the procedure.]

Patients below 18 years of age, history of inflammatory bowel disease, colonoscopy failure due to reasons other than inadequate bowel preparation was excluded from this study. All procedures were performed in the morning without any sedation.

All patients referred for colonoscopy procedure were requested to fill in the pre-procedural questionnaire form. The following data were collected: age, sex, hospital status (inpatient or outpatient), weight, height, indication for colonoscopy, comorbidities, bowel frequency pattern, current medications, past history of colonic or pelvic surgery, physical activity, volume of solution prepared and compliance with preparation instructions (non-compliance defined as failure to complete $75 \%$ of the prepared solution). Constipation was defined according to the Rome III diagnostic criteria for functional gastrointestinal disorders ${ }^{13}$ and body mass index (BMI) was calculated by using the standard formula [weight $(\mathrm{kg}) /$ height $\left.(\mathrm{m})^{2}\right]$.

Ethical approval was taken from the Institutional Review Committee of KMCTH (ref. 310520110) and informed consent was taken from the patients.

The quality of preparation was graded based on the Aronchick scale ${ }^{14}$ as Excellent, Good, Fair, Poor and Inadequate. Patients were divided into adequate (excellent, good) and inadequate (fair, poor) groups. Fair appearance on colonoscopy was placed in inadequate group as they were kept on shorter follow-up for next colonoscopy procedure.

Data were analyzed by calculating descriptive statistics for demographic variables and preparation characteristics. Each variable was tested for related association with inadequate preparation. Possible predictors of inadequate bowel preparation defined by Aronchick scale were analyzed using univariate and multivariate logistic regression models. All statistical analyses were performed using the SPSS software package, version 20 (Statistical Package for the Social Sciences, IBM Corporation, Armonk, NY, USA). Variables with $p$ value $<0.05$ were considered significant.

\section{RESULTS}

\section{Patient characteristics}

During this study period, 138 colonoscopy procedures were performed out of which 119 (86.2\%) preparations were adequate and $19(13.8 \%)$ were inadequate. The mean age of the patient was 52.62 ( $S D \pm 10.51$ ) years, out of which, 82 (59.4\%) were male and $56(40.6 \%)$ were female.

Comparisons of characteristic between patients with and without adequate bowel preparation for colonoscopy are shown in Table 2. Difference in characteristic frequency between the two outcome groups with a $p$ value of $<0.05$ was considered significant. Patients with constipation, overweight $\left(25-29.9 \mathrm{~kg} / \mathrm{m}^{2}\right)$, age $>60$ years, neurological issues like stroke or dementia, use of antidepressant drugs, compliance (consumption of less than $75 \%$ of the PEG solution) were significant univariate predictors of inadequate bowel preparation. In the multivariate analysis, constipation [adjusted OR 8.55, 
95\% Cl 1.79-41.67] and non-compliance [adjusted OR

$58.82,95 \%$ Cl 5.99-500] were independently associated with inadequate bowel preparation. Other factors previously significant in the univariate analysis were not statistically significant in the multivariate analysis.

Table 1: Patient demographic and characteristics $(n=138)$

\begin{tabular}{|c|c|}
\hline Mean age (years) & $52.62( \pm 10.51)$ \\
\hline \multicolumn{2}{|l|}{ Age } \\
\hline$>60$ years & $35(25.4 \%)$ \\
\hline$<60$ years & $103(74.6 \%)$ \\
\hline Gender (M/F) & $82(59.4 \%) / 56(40.6 \%)$ \\
\hline \multicolumn{2}{|l|}{ BMI } \\
\hline Underweight $\left(<18.5 \mathrm{~kg} / \mathrm{m}^{2}\right)$ & $0(0 \%)$ \\
\hline Normal $\left(18.5-24.9 \mathrm{~kg} / \mathrm{m}^{2}\right)$ & $125(90.6 \%)$ \\
\hline Overweight $\left(25-29.9 \mathrm{~kg} / \mathrm{m}^{2}\right)$ & $13(9.4 \%)$ \\
\hline Obese $\left(>30 \mathrm{~kg} / \mathrm{m}^{2}\right)$ & $0(0 \%)$ \\
\hline Constipation & $16(11.6 \%)$ \\
\hline History of previous surgery & $5(3.6 \%)$ \\
\hline Compliance & $128(92.8 \%)$ \\
\hline \multicolumn{2}{|l|}{ Preparation } \\
\hline Adequate & $119(86.2 \%)$ \\
\hline Inadequate & $19(13.8 \%)$ \\
\hline \multicolumn{2}{|l|}{ Comorbidities } \\
\hline Hypertension & $33(23.9 \%)$ \\
\hline Diabetes mellitus & $8(5.8 \%)$ \\
\hline Stroke / Dementia & $4(2.9 \%)$ \\
\hline Hypothyroidism & $5(3.6 \%)$ \\
\hline \multicolumn{2}{|l|}{ Medications } \\
\hline Opioids & $0(0 \%)$ \\
\hline Antidepressant / Antipsychotic & $3(2.2 \%)$ \\
\hline BMI- body mass index; $M$ - male; F- female & \\
\hline
\end{tabular}

Table 2: Univariate analysis of predictors for inadequate bowel preparation

\begin{tabular}{lccc}
\hline & Adequate preparation $(\mathbf{n = 1 1 9 )}$ & Inadequate preparation (n= 19) & P-value \\
\hline Male gender [N (\%)] & $69(58)$ & $13(68.4)$ & 0.390 \\
\hline Female gender [N (\%)] & $50(42)$ & $6(31.6)$ & 0.390 \\
\hline Age [ >=60 years [N (\%)] & $24(20.2)$ & $11(57.9)$ & 0.000 \\
\hline Overweight [N (\%)] & $7(5.9)$ & $6(31.6)$ & 0.000 \\
\hline Constipation [N (\%)] & $6(5)$ & $10(52.6)$ & 0.000 \\
\hline Abdominal surgery [N (\%)] & $4(3.4)$ & $1(5.3)$ & 0.680 \\
\hline Diabetes [N (\%)] & $7(5.9)$ & $1(5.3)$ & 0.915 \\
\hline Stroke/Dementia [N (\%)] & $1(0.8)$ & $3(15.8)$ & 0.000 \\
\hline Tricyclic use [N (\%)] & $1(0.8)$ & $2(10.5)$ & 0.007 \\
Compliance [N (\%)] & $118(99.2)$ & $10(52.6)$ & 0.000 \\
Hypothyroidism [N (\%)] & $2(1.7)$ & $2(10.5)$ & 0.033 \\
Calcium Channel Blocker use [N (\%)] & $3(100)$ & 0 & 0.484 \\
\hline
\end{tabular}


Table 3: Multivariate analysis of predictors of inadequate bowel preparation

\begin{tabular}{lcccc} 
& P- value & Adjusted odd's ratio & Lower & 95\% C.I. \\
Constipation & .007 & 8.55 & 1.79 & Upper \\
\hline Non-compliance & .000 & 58.82 & 5.99 & 51.67 \\
\hline Hypothyroidism & .029 & 12.35 & 1.29 & 125 \\
\hline Overweight & .173 & 3.69 & 0.56 & 2.44 \\
\hline Age $>$ 60 years & .355 & 2.06 & 0.45 & 9.43 \\
\hline Stroke/ Dementia & .168 & 8.62 & 0.40 & 200 \\
\hline Antidepressant use & .731 & 1.83 & 0.05 & 58.82 \\
\hline
\end{tabular}

Note: $\mathrm{p}<0.05$ considered significant. Both forward and backward models used to decide the final model.

\section{DISCUSSION}

In this prospective study, we examined the predicting factors for inadequate bowel preparation using two litres of PEG solution. Our results showed $13.8 \%$ of patients undergoing colonoscopy had inadequate bowel preparation, which was consistent with other studies $^{7,8,15}$. However, our percentage of inadequate bowel preparation is less than the previous reports of nearly $30 \%$ in patients using PEG solution for bowel cleaning ${ }^{16}$.

We identified several patient characteristics that were independently associated with inadequate bowel preparation, which included constipation, overweight, age $>60$ years, neurological issues like stroke or dementia, use of anti-depressant drugs and compliance. Patient compliance to bowel preparation technique is an important factor to adequate bowel preparation. We identified that $6.5 \%$ of our patients were noncompliant to the preparation instructions. When asked about the reason for non-compliance, they described nausea and vomiting were the primary reasons. We believe preparation with low volume of drinking and low emetic effect would reduce the adverse effect, thereby increasing the compliance. Some studies have shown that misunderstanding the preparation instructions as an important factor for poor preparation quality ${ }^{15}$. Therefore, patient's education could be an efficient option in improving bowel preparation ${ }^{17,18}$. Another factor for inadequate bowel preparation could be timing of the procedure. Studies have shown that afternoon colonoscopies might have lower success rates with more frequent inadequate bowel preparations ${ }^{19}$. Adequate bowel preparation could be achieved if the optimal interval between the last dose of PEG solution and start of colonoscopy was 3-5 hours ${ }^{20}$.

Out of the other predictors of inadequate bowel preparation, we identified that, our patients with altered bowel motility were associated with inadequate colonic preparation. Factors like chronic or severe constipation due to intestinal dysmotility, anticholinergic effect of tricyclic antidepressant drugs, and altered bowel motility in hypothyroidism, stroke and dementia were independent risk factors. Constipation and noncompliance were significant predictors in univariate as well as multivariate analysis. The presence of diabetes has been reported as an independent factor for incomplete bowel preparation, 7,8,21 however, in our study diabetes was not a significant $(\mathrm{P}=0.915)$ predictor for inadequate bowel preparation. Hospitalized, bed bound patients are also reported to be independent predictors of incomplete bowel preparation due to decreased intestinal motility and non-compliance due to underlying disease ${ }^{7,22}$. Previous intestinal surgeries have been reported as a predicting factor for inadequate bowel preparation. This could be secondary to altered bowel motility and advancing age. In our study, previous intestinal surgery was not associated with inadequate bowel preparation $(\mathrm{P}=0.680)$.

Obesity is a common metabolic disorder associated with multiple gastrointestinal disorders like colonic polyps and colorectal cancers ${ }^{23}$. The impact of obesity on bowel preparation has mixed results till date. Some studies have shown that high BMI $(>30 \mathrm{~kg} / \mathrm{m} 2)$ is independently associated with inadequate bowel preparation ${ }^{24,25}$ while others showing no significant impact ${ }^{7} 26$. Our study had $9.4 \%$ of overweight patients and was identified as an independent predicting factor $(P=0.000)$ for inadequate bowel preparation. Of note, none of our patients were under weight or obese.

Additionally, low socioeconomic status and low health literacy were identified as risk factors because patients were not following the preparation instructions ${ }^{22}, 27$. Low health education may result in poor understanding of the requirement therefore unable to comply with 
the instructions. Our study indicates that few patient specific variables may help to predict patients at risk for inadequate bowel preparation for whom alternative techniques could be employed. In such cases, low fiber diet for 3 days followed by liquid diet only the day before colonoscopy and split dose PEG consumption (one litre in the evening, one litre early morning on the day of procedure) was advised.

Our study has few limitations. This is a single institution study with limited number of patients. Another factor not considered in this study was socioeconomic status and low health literacy of the patient.

\section{REFERENCES}

1. Peery AF, Dellon ES, Lund J, Crockett SD, McGowan $\mathrm{CE}$, Bulsiewicz WJ, et al. Burden of gastrointestinal disease in the United States: 2012 update. Gastroenterology. 2012;143(5):1179-87. [PubMed]

2. Hassan C, Bretthauer M, Kaminski MF, Polkowski M, Rembacken B, Saunders B, et al. Bowel preparation for colonoscopy: European Society of Gastrointestinal Endoscopy (ESGE) guideline. Endoscopy. 2013;45(2):142-50. [PubMed]

3. Canard J, Heresbach D, Letard J-C, Laugier R. Colonoscopy in France in 2008: results of the two-day survey of endoscopy in France. ACTA ENDOSCOPICA. 2010;40(2):58-65.

4. Harewood GC, Sharma VK, de Garmo P. Impact of colonoscopy preparation quality on detection of suspected colonic neoplasia. Gastrointest Endosc. 2003;58(1):76-9. [PubMed]

5. Froehlich F, Wietlisbach V, Gonvers JJ, Burnand B, Vader JP. Impact of colonic cleansing on quality and diagnostic yield of colonoscopy: the European Panel of Appropriateness of Gastrointestinal Endoscopy European multicenter study. Gastrointest Endosc. 2005;61(3):378-84. [PubMed]

6. Belsey J, Epstein O, Heresbach D. Systematic review: oral bowel preparation for colonoscopy. Alimentary pharmacology \& therapeutics. 2007;25(4):373-84. [PubMed]

7. Ness RM, Manam R, Hoen H, Chalasani N. Predictors of inadequate bowel preparation for colonoscopy. Am J Gastroenterol. 2001;96(6):1797-802. [PubMed]

8. Hassan C, Fuccio L, Bruno M, Pagano N, Spada C, Carrara $S$, et al. A predictive model identifies patients most likely to have inadequate bowel preparation for colonoscopy. Clin Gastroenterol Hepatol. 2012;10(5):501-6. [PubMed]

\section{CONCLUSION}

Inadequately prepared bowel affects the diagnostic yield of colonoscopy thereby increasing the cost with repeated procedures and delay in diagnosis. We found, constipation, non-compliance, overweight, neurological disorders like stroke, dementia and age >60 years were associated with inadequate bowel preparation. If patients with a high risk of inadequate preparation can be identified early, salvage options could be used to improve the quality of bowel preparation.

\section{Conflict of interest: None}

Source(s) of support: None

9. Hautefeuille G, Lapuelle J, Chaussade S, Ponchon T, Molard BR, Coulom P, et al. Factors related to bowel cleansing failure before colonoscopy: Results of the PACOME study. United European Gastroenterol J. 2014;2(1):22-9. [PubMed]

10. Gorard DA, Libby GW, Farthing MJ. Influence of antidepressants on whole gut and orocaecal transit times in health and irritable bowel syndrome. Aliment Pharmacol Ther. 1994;8(2):159-66. [PubMed]

11. Frommer D. Cleansing ability and tolerance of three bowel preparations for colonoscopy. Dis Colon Rectum. 1997;40(1):100-4. [PubMed]

12. Hsu CW, Imperiale TF. Meta-analysis and cost comparison of polyethylene glycol lavage versus sodium phosphate for colonoscopy preparation. Gastrointest Endosc. 1998;48(3):276-82. [PubMed]

13. Longstreth GF, Thompson WG, Chey WD, Houghton LA, Mearin F, Spiller RC. Functional bowel disorders. Gastroenterology. 2006;130(5):1480-91. [PubMed]

14. Aronchick CA, Lipshutz WH, Wright SH, Dufrayne F, Bergman G. A novel tableted purgative for colonoscopic preparation: efficacy and safety comparisons with Colyte and Fleet Phospho-Soda. Gastrointest Endosc. 2000;52(3):346-52. [PubMed]

15. Nguyen DL, Wieland M. Risk factors predictive of poor quality preparation during average risk colonoscopy screening: the importance of health literacy. J Gastrointestin Liver Dis. 2010;19(4):369-72. [PubMed]

16. Chung YW, Han DS, Park KH, Kim KO, Park CH, Hahn T, et al. Patient factors predictive of inadequate bowel preparation using polyethylene glycol: a prospective study in Korea. J Clin Gastroenterol. 2009;43(5):44852. [PubMed]

17. Abuksis G, Mor M, Segal N, Shemesh I, Morad I, Plaut $\mathrm{S}$, et al. A patient education program is cost-effective for preventing failure of endoscopic procedures in a 
gastroenterology department. Am J Gastroenterol. 2001;96(6):1786-90. [PubMed]

18. Rosenfeld G, Krygier D, Enns RA, Singham J, Wiesinger $\mathrm{H}$, Bressler B. The impact of patient education on the quality of inpatient bowel preparation for colonoscopy. Can J Gastroenterol. 2010;24(9):543-6. [PubMed]

19. Wells CD, Heigh RI, Sharma VK, Crowell MD, Gurudu $\mathrm{SR}$, Leighton JA, et al. Comparison of morning versus afternoon cecal intubation rates. BMC Gastroenterol. 2007;7(19):7-19. [PubMed]

20. Seo EH, Kim TO, Park MJ, Joo HR, Heo NY, Park $\mathrm{J}$, et al. Optimal preparation-to-colonoscopy interval in split-dose PEG bowel preparation determines satisfactory bowel preparation quality: an observational prospective study. Gastrointest Endosc. 2012;75(3):583-90. [PubMed]

21. Taylor C, Schubert ML. Decreased efficacy of polyethylene glycol lavage solution (golytely) in the preparation of diabetic patients for outpatient colonoscopy: a prospective and blinded study. Am J Gastroenterol. 2001;96(3):710-4. [PubMed]
22. Lebwohl B, Wang TC, Neugut Al. Socioeconomic and other predictors of colonoscopy preparation quality. Dig Dis Sci. 2010;55(7):2014-20. [PubMed]

23. Neugut AI, Lee WC, Garbowski GC, Waye JD, Forde KA, Treat MR, et al. Obesity and colorectal adenomatous polyps. J Natl Cancer Inst. 1991;83(5):359-61. [PubMed]

24. Borg BB, Gupta NK, Zuckerman GR, Banerjee B, Gyawali CP. Impact of obesity on bowel preparation for colonoscopy. Clin Gastroenterol Hepatol. 2009;7(6):670-5. [PubMed]

25. Fayad NF, Kahi CJ, Abd El-Jawad KH, Shin AS, Shah $\mathrm{S}$, Lane KA, et al. Association between body mass index and quality of split bowel preparation. Clin Gastroenterol Hepatol. 2013;11(11):1478-85. [PubMed]

26. Gurudu SR, Ratuapli S, Heigh R, DiBaise J, Leighton J, Crowell M. Quality of bowel cleansing for afternoon colonoscopy is influenced by time of administration. Am J Gastroenterol. 2010;105(11):2318-22. [PubMed]

27. Menees SB, Kim HM, Wren P, Zikmund-Fisher BJ, Elta $\mathrm{GH}$, Foster $\mathrm{S}$, et al. Patient compliance and suboptimal bowel preparation with split-dose bowel regimen in average-risk screening colonoscopy. Gastrointest Endosc. 2014;79(5):811-20. [PubMed] 